\title{
Lifetime prevalence of psychiatric disorders in South Africa
}

Dan J. Stein, Soraya Seedat, Allen Herman, Hashim Moomal, Steven G. Heeringa, Ronald C. Kessler and David R. Williams

\section{Background}

Data on the lifetime prevalence of psychiatric disorders in South Africa are of interest, not only for the purposes of developing evidence-based mental health policy, but also in view of South Africa's particular historical and demographic circumstances.

\section{Method}

A nationally representative household survey was conducted between 2002 and 2004 using the World Health Organization Composite International Diagnostic Interview (CIDI) to generate diagnoses. The data-set analysed included 4351 adult South Africans of all ethnic groups.

\section{Results}

Lifetime prevalence of DSM-IV/CIDI disorders was determined for anxiety disorders (15.8\%), mood disorders
(9.8\%), substance use disorders (13.4\%) and any disorder (30.3\%). Lifetime prevalence of substance use disorders differed significantly across ethnic groups. Median age at onset was earlier for substance use disorders (21 years) than for anxiety disorders (32 years) or mood disorders (37 years).

\section{Conclusions}

In comparison with data from other countries, South Africa has a particularly high lifetime prevalence of substance use disorders. These disorders have an early age at onset, providing an important target for the planning of local mental health services.

\section{Declaration of interest}

None. Funding detailed in Acknowledgements.
To date, no nationally representative data have been available on the prevalence of psychiatric disorders in South Africa. Such data are clearly important for rigorous local mental health service planning. Furthermore, given the particular circumstances of South Africa's colonial and apartheid past, and its recent emergence as a democracy, such data are also relevant to understanding more global issues and processes, including social disparities in health and mechanisms of vulnerability and resilience to psychopathological disorders. The lack of epidemiological data on psychiatric disorders in South Africa is consistent with a relative lack of data from elsewhere in the continent. The 12-month prevalence of any psychiatric disorder in the Yoruba-speaking part of Nigeria was recently reported as $4.7 \%$, one of the lowest rates in 14 countries participating in the World Mental Health Surveys. ${ }^{1}$ The precise reasons underlying the low estimated prevalence are unclear, but underreporting to lay interviewers or the social capital held by African societies may be relevant factors.

There are several reasons to believe that the prevalence of psychiatric disorder in South Africa would be relatively high. Stressors such as racial discrimination and political violence have been perennial in the past, and high rates of gender inequality and criminal violence are reportedly a feature in the present. ${ }^{2,3}$ Poverty remains a significant problem, and is likely to contribute to vulnerability to common psychiatric disorders in low-income countries. ${ }^{4}$ On the other hand, features of South African society may predict a more complex picture. The country's socioeconomic history has resulted in different ethnic groups having distinct socio-economic profiles, with the White population advantaged and the Black population disadvantaged. Socioeconomic privilege might protect against stressors and reduce prevalence of psychiatric disorder. Alternatively, factors reducing the prevalence of psychiatric disorder in Nigeria might also operate in some sectors of society. As a result, prevalence of psychiatric disorders in South Africa might be posited to lie between that reported in high-income countries ${ }^{5,6}$ and that of Nigeria.

\section{Method}

\section{Sample}

The South African Stress and Health (SASH) Study was a national probability sample of adult South Africans living in households or in hostel quarters, with data obtained between January 2002 and June 2004 . $^{7}$ Hostel quarters were included to maximise coverage of young working-age men. The sample did not include individuals in institutions or in the military. Individuals of all ethnic backgrounds were included in the study. The sample was selected using a three-stage probability sample design. The first stage involved selecting a stratified probability sample of primary sampling areas equivalent to counties in the USA or the UK, based on the 2001 South African Census of Enumeration Areas. The enumeration areas were sampled with probabilities proportionate to population size. The second stage involved selecting an equalprobability sample of housing units within each enumeration area. The third stage involved selecting one adult respondent from each sample housing unit; interviewers selected a single adult at random using the Kish procedure for objective respondent selection. ${ }^{8}$ If the household or the selected respondent refused to be interviewed, a random replacement was drawn from the enumerative listing for the area. A total sample of 5089 households were selected for the SASH Study. Field interviews were obtained with $4433(87.1 \%)$ of the designated respondents. Based on quality control criteria, 4351 (85.5\%) of the field interviews were retained for use in the analysis. There was no difference in response rates across ethnic groups.

\section{Diagnostic interview}

The diagnostic interview used in the SASH Study was version 3.0 of the World Health Organization (WHO) Composite International Diagnostic Interview (CIDI), ${ }^{9}$ a fully structured layadministered interview that generates diagnoses according to the 
criteria of both the ICD-10 and DSM-IV diagnostic systems. In view of time constraints, however, the interview excluded a number of disorders (e.g. specific phobia and impulse control disorders other than intermittent explosive disorder). The DSM-IV criteria ${ }^{10}$ are used in the current report. Interviewers were trained in the administration of the CIDI in centralised group sessions lasting 1 week. The interviews were conducted face-to-face in seven different languages: English, Afrikaans, Zulu, Xhosa, North Sotho, South Sotho and Tswana. The protocol was reviewed by the ethics committee of the Medical University of South Africa, and all participants gave informed consent. Interviews lasted an average of $3 \frac{1}{2} \mathrm{~h}$, with some requiring more than one visit to complete.

\section{Statistical analysis}

The person-level SASH data were weighted to adjust for differential probabilities of selection within households, differential nonresponse and residual discrepancies between the sample and the population on a profile of census demographic and geographic variables. These weights were used in all data analyses. Data analysis was carried out using SAS and SAS-Callable SUDAAN version 8.2 software to adjust estimates of statistical significance for the weighting and clustering of the data. Statistical methods included standard estimates of prevalence, multivariate analyses of socio-demographic predictors of lifetime risk, and the actuarial method to generate survival distributions from retrospective disorder age-at-onset reports. Discrete-time hazard models ${ }^{11}$ were used to examine the joint effects of person-year (each year in the life of each respondent up to their age at interview), gender, ethnicity and age at interview (18-34, 35-49, 50-64 and 65+ years) in predicting first onset of each disorder. Non-proportionalities in hazards were evaluated by considering the possibility that the predictive effects of gender and age at interview differ across life-course stages defined by person-year. Statistical significance was evaluated using two-sided tests $(P=0.05)$ that adjusted for the weighting and clustering of the data.

\section{Results}

\section{Lifetime prevalence}

The most prevalent lifetime DSM-IV/CIDI disorders (Table 1) were alcohol abuse (11.4\%), major depression (9.8\%) and agoraphobia $(9.8 \%)$. The most prevalent class of disorder was estimated to be anxiety disorders $(15.8 \%)$, followed by substance use disorders (13.3\%) and mood disorders (9.8\%). The lifetime prevalence estimate of any disorder was $30.3 \%$, with $11.2 \%$ of respondents having two and 3.5\% having three or more disorders. Disorders with very low prevalence such as dysthymia or intermittent explosive disorder are not tabulated.

Lifetime prevalence estimates varied significantly with age at interview for several disorders, including panic disorder (highest in the cohorts of respondents who were in midlife at the time of interview), generalised anxiety disorder (increasing prevalence in successively earlier cohorts) and drug dependence (decreasing prevalence in successively earlier cohorts) (Table 1). However, the prevalence of any anxiety disorder and of alcohol abuse were remarkably consistent across cohorts.

Mood and anxiety disorders were significantly associated with female gender, whereas substance use disorders were significantly associated with male gender (Table 2). There was a significant positive association between age range 35-49 years and mood disorders, and significant associations between the White group and intermittent explosive disorder, and between the Coloured group ('Coloured' is an apartheid-era ethnic designation still used for demographic purposes) and substance use disorders (Table 2). Only a few other socio-demographic associations were significantly associated with mental disorders, including an association between being divorced, separated or widowed and having any disorder or mood disorder (Table 2).

\section{Age at onset}

The age-at-onset distributions were standardised to facilitate ease of interpretation (Table 3). Median age at onset (i.e. the 50th

Table 1 Lifetime prevalence of psychiatric disorders

\begin{tabular}{|c|c|c|c|c|c|c|c|c|c|}
\hline \multirow[b]{2}{*}{ Disorder $^{a}$} & \multirow[b]{2}{*}{$n$} & \multirow[b]{2}{*}{$\begin{array}{c}\text { Total } \\
\% \text { (s.e.) }\end{array}$} & \multicolumn{4}{|c|}{ Age group, years } & \multirow[b]{2}{*}{$\chi^{2}$} & \multirow[b]{2}{*}{ d.f. } & \multirow[b]{2}{*}{$P$} \\
\hline & & & $\begin{array}{c}18-34 \\
\% \text { (s.e) }\end{array}$ & $\begin{array}{l}\text { 35-39 } \\
\% \text { (s.e) }\end{array}$ & $\begin{array}{c}50-64 \\
\% \text { (s.e) }\end{array}$ & $\begin{array}{c}65+ \\
\% \text { (s.e) }\end{array}$ & & & \\
\hline \multicolumn{10}{|l|}{ Anxiety disorders } \\
\hline Panic disorder & 57 & $1.2(0.2)$ & $0.6(0.2)$ & $1.9(0.4)$ & $1.9(0.7)$ & $1.3(0.9)$ & 10.3 & 3 & 0.022 \\
\hline Generalised anxiety disorder & 124 & $2.7(0.3)$ & $1.2(0.2)$ & $3.7(0.4)$ & $4.1(1.0)$ & $7.2(2.5)$ & 40.5 & 3 & $<0.001$ \\
\hline Social phobia & 116 & $2.8(0.4)$ & $2.7(0.5)$ & $3.5(0.7)$ & $2.5(0.9)$ & $1.3(0.8)$ & 3.7 & 3 & 0.305 \\
\hline Agoraphobia without panic & 435 & $9.8(0.6)$ & $10.5(1.0)$ & $10.0(1.0)$ & $8.1(1.4)$ & $7.2(1.7)$ & 4.7 & 3 & 0.204 \\
\hline PTSD & 91 & $2.3(0.3)$ & $1.8(0.3)$ & $2.4(0.6)$ & $2.7(0.7)$ & $4.4(2.9)$ & 1.5 & 3 & 0.689 \\
\hline Any anxiety disorder & 695 & $15.8(0.8)$ & $14.7(1.1)$ & $17.6(1.1)$ & $15.9(2.0)$ & $17.0(3.3)$ & 3.6 & 3 & 0.320 \\
\hline \multicolumn{10}{|l|}{ Mood disorders } \\
\hline MDD with hierarchy & 439 & $9.8(0.7)$ & $8.9(0.8)$ & $11.9(1.3)$ & $10.0(1.3)$ & $6.5(1.6)$ & 8.2 & 3 & 0.052 \\
\hline \multicolumn{10}{|l|}{ Substance use disorders } \\
\hline Alcohol abuse & 435 & $11.4(0.8)$ & $11.1(1.1)$ & $12.8(1.5)$ & $10.0(1.8)$ & $10.3(3.3)$ & 2.2 & 3 & 0.543 \\
\hline Alcohol dependence & 95 & $2.6(0.4)$ & $2.3(0.5)$ & $3.5(0.8)$ & $1.9(0.9)$ & $2.5(1.4)$ & 2.3 & 3 & 0.513 \\
\hline Drug abuse without dependence & 139 & $3.9(0.4)$ & $4.6(0.6)$ & $4.2(0.8)$ & $2.0(0.7)$ & $1.6(0.9)$ & 12.2 & 3 & 0.011 \\
\hline Drug dependence with abuse & 19 & $0.6(0.2)$ & $0.8(0.3)$ & $0.5(0.3)$ & $0.2(0.2)$ & $0.0(0.0)$ & 11.9 & 3 & 0.012 \\
\hline Any substance use & 505 & $13.3(0.9)$ & $13.5(1.2)$ & $14.7(1.6)$ & $11.0(1.9)$ & $11.0(3.3)$ & 3.5 & 3 & 0.334 \\
\hline \multicolumn{10}{|l|}{ All disorders } \\
\hline Any disorder & 1290 & $30.3(1.1)$ & $29.4(1.4)$ & $33.6(2.0)$ & $28.3(2.6)$ & $27.9(3.4)$ & 6.1 & 3 & 0.119 \\
\hline Two or more disorders & 456 & $11.2(0.8)$ & $10.4(1.0)$ & $12.8(1.2)$ & $11.2(1.7)$ & $9.6(3.0)$ & 3.1 & 3 & 0.384 \\
\hline Three or more disorders & 139 & $3.5(0.5)$ & $3.2(0.6)$ & $4.8(0.8)$ & $2.5(0.9)$ & $2.8(2.1)$ & 5.1 & 3 & 0.176 \\
\hline
\end{tabular}




\begin{tabular}{|c|c|c|c|c|c|}
\hline & $\begin{array}{l}\text { Any disorder } \\
\text { OR }(95 \% \mathrm{Cl})\end{array}$ & $\begin{array}{l}\text { Mood disorder } \\
\text { OR }(95 \% \mathrm{Cl})\end{array}$ & $\begin{array}{l}\text { Anxiety disorder } \\
\text { OR }(95 \% \mathrm{Cl})\end{array}$ & $\begin{array}{c}\text { IED } \\
\text { OR }(95 \% \mathrm{Cl})\end{array}$ & $\begin{array}{l}\text { Substance use disorder } \\
\text { OR }(95 \% \mathrm{Cl})\end{array}$ \\
\hline \multicolumn{6}{|l|}{ Gender } \\
\hline Male & 1.00 & 1.00 & 1.00 & 1.00 & 1.00 \\
\hline Female & $\begin{array}{c}0.92(0.8-1.1) \\
\chi^{2}=0.74, P=0.39\end{array}$ & $\begin{array}{c}1.78(1.3-2.4)^{*} \\
\chi^{2}=15.3, P<0.01\end{array}$ & $\begin{array}{c}1.79(1.5-2.2)^{\star} \\
\chi^{2}=30.4, P<0.01\end{array}$ & $\begin{array}{c}0.70(0.5-1.0)^{*} \\
\chi^{2}=4.18, P=0.04\end{array}$ & $\begin{array}{c}0.27(0.2-0.3)^{\star} \\
\chi^{2}=98.2, P<0.01\end{array}$ \\
\hline \multicolumn{6}{|l|}{ Age, years } \\
\hline 18-34 & $1.09(0.7-1.6)$ & $1.40(0.8-2.5)$ & $0.83(0.5-1.4)$ & $2.75(0.9-8.9)$ & $1.26(0.6-2.7)$ \\
\hline $35-49$ & $1.34(1.0-1.9)$ & $1.95(1.1-3.6)^{*}$ & $1.04(0.6-1.7)$ & $3.61(1.0-13.0)^{*}$ & $1.40(0.7-2.7)$ \\
\hline $50-64$ & $1.02(0.7-1.5)$ & $1.59(0.9-2.9)$ & $0.91(0.6-1.5)$ & $2.23(0.5-9.1)$ & $0.99(0.5-1.9)$ \\
\hline \multirow[t]{2}{*}{$65+$} & 1.00 & 1.00 & 1.00 & 1.00 & 1.00 \\
\hline & $\chi^{2}=8.02, P=0.05$ & $\chi^{2}=8.93, P=0.03$ & $\chi^{2}=4.01, P=0.26$ & $\chi^{2}=5.51, P=0.14$ & $\chi^{2}=3.22, P=0.36$ \\
\hline \multicolumn{6}{|l|}{ Ethnicity } \\
\hline Black & 1.00 & 1.00 & 1.00 & 1.00 & 1.00 \\
\hline Coloured & $1.27(1.0-1.7)$ & $1.08(0.8-1.5)$ & $0.94(0.6-1.4)$ & $1.55(0.8-3.2)$ & $1.60(1.1-2.3)^{\star}$ \\
\hline White & $0.92(0.5-1.7)$ & $0.89(0.4-2.2)$ & $0.68(0.3-1.4)$ & $3.02(1.3-7.0)^{\star}$ & $1.21(0.7-2.0)$ \\
\hline Indian & $0.83(0.6-1.2)$ & $1.43(0.7-3.1)$ & $0.65(0.3-1.2)$ & $1.48(0.6-3.5)$ & $0.40(0.2-1.0)$ \\
\hline & $\chi^{2}=5.76, P=0.12$ & $\chi^{2}=0.96, P=0.81$ & $\chi^{2}=2.93, P=0.40$ & $\chi^{2}=7.49, P=0.06$ & $\chi^{2}=12.9, P<0.01$ \\
\hline \multicolumn{6}{|l|}{ Income } \\
\hline Low & $0.80(0.6-1.0)$ & $0.94(0.7-1.4)$ & $0.91(0.7-1.2)$ & $0.45(0.3-0.8)^{\star}$ & $0.73(0.5-1.0)^{*}$ \\
\hline Low average & $0.69(0.6-0.9)^{\star}$ & $0.92(0.6-1.3)$ & $0.78(0.6-1.1)$ & $0.43(0.2-1.0)$ & $0.63(0.5-0.9)^{*}$ \\
\hline High average & $0.90(0.7-1.2)$ & $0.60(0.3-1.1)$ & $1.17(0.8-1.8)$ & $0.49(0.1-1.9)$ & $0.92(0.6-1.4)$ \\
\hline High & 1.00 & 1.00 & 1.00 & 1.00 & 1.00 \\
\hline & $\chi^{2}=11.0, P=0.01$ & $\chi^{2}=4.00, P=0.26$ & $\chi^{2}=3.95, P=0.27$ & $\chi^{2}=8.97, P=0.03$ & $\chi^{2}=9.49, P=0.02$ \\
\hline \multicolumn{6}{|l|}{ Marital status } \\
\hline Married & 1.00 & 1.00 & 1.00 & 1.00 & 1.00 \\
\hline Separated/divorced/widowed & $1.49(1.1-2.0)^{*}$ & $2.20(1.6-3.1)^{*}$ & $1.41(1.0-2.1)$ & $0.85(0.4-1.9)$ & $1.20(0.8-1.8)$ \\
\hline Never married & $1.02(0.8-1.2)$ & $0.94(0.7-1.2)$ & $0.99(0.8-1.2)$ & $1.06(0.6-1.8)$ & $1.16(0.9-1.5)$ \\
\hline & $\chi^{2}=7.05, P=0.03$ & $\chi^{2}=23.2, P<0.01$ & $\chi^{2}=3.58, P=0.17$ & $\chi^{2}=0.45, P=0.80$ & $\chi^{2}=1.92, P=0.38$ \\
\hline \multicolumn{6}{|l|}{ Education } \\
\hline None & $0.88(0.6-1.3)$ & $0.93(0.5-1.8)$ & $1.18(0.7-2.0)$ & $0.94(0.3-3.1)$ & $0.64(0.4-1.0)$ \\
\hline Primary & $1.07(0.8-1.5)$ & $2.01(1.2-3.3)^{\star}$ & $1.08(0.7-1.6)$ & $0.49(0.2-1.2)$ & $0.70(0.5-0.9)^{*}$ \\
\hline Secondary & $0.97(0.8-1.2)$ & $1.25(0.8-1.9)$ & $1.11(0.8-1.6)$ & $0.97(0.4-2.6)$ & $0.83(0.6-1.1)$ \\
\hline \multirow{2}{*}{ University } & 1.00 & 1.00 & 1.00 & 1.00 & 1.00 \\
\hline & $\chi^{2}=1.79, P=0.62$ & $\chi^{2}=14.6, P<0.01$ & $\chi^{2}=0.45, P=0.93$ & $\chi^{2}=5.30, P=0.15$ & $\chi^{2}=6.69, P=0.08$ \\
\hline
\end{tabular}

percentile on the distribution) was earlier for substance use disorders (24 years) than for anxiety disorders (32 years) or mood disorders (37 years). Age at onset varied widely within particular disorders, with the interquartile ranges (IQR) - the number of years between the 25th and 75th percentiles - ranging from 11 years (20-31 years) for substance use disorders to 30 years for depression (23-53 years) and 41 years (16-57 years) for anxiety disorders. In the case of substance use disorders, both alcohol and drug abuse had early ages at onset and narrow IQRs. There was considerably more variation, in comparison, in the case of anxiety disorders, where social phobia and agoraphobia had an early median age at onset and comparatively narrow IQR; panic and post-traumatic stress disorder (PTSD) fell in the middle in terms of age at onset and width of IQR, and generalised anxiety disorder had a comparatively late age at onset and the widest IQR.

\section{Cohort effects}

Dummy variables defining cohorts with ages at interview in the range 18-29 years (born 1973-1986), 30-44 years (born 19611972), 45-59 (born 1949-1960) and 60 years or over (born before 1948) were used to predict lifetime disorders using discrete-time survival analysis. The odds ratios were statistically significant in several comparisons, with a positive association between recency of cohort and magnitude of odds ratio (Table 4). This was particularly the case for major depression, where the largest cohort effects were obtained. However, non-significant odds ratios and small cohort effects were apparent in the case of generalised anxiety disorder and PTSD, as well as in substance abuse cohorts other than the most recent one.

These models were then refined to determine whether cohort effects differ by life-course stage. Little evidence of such variation was found for substance use disorders (data not shown). In contrast, more inter-cohort variation in risk of first onset was found in the middle years of life for anxiety disorders and in later life for mood disorders. Socio-demographic variables significantly related to onset of psychiatric disorders were consistent with those noted above (data not shown). Thus, women had a significantly higher risk than men of anxiety and mood disorders onset whereas men had a significantly higher risk of substance use disorders onset, and there was no significant association with ethnicity. Furthermore, in an analysis that examined inter-cohort differences in demographic effects, no interaction with cohort was found for gender, ethnicity or education (data not shown), indicating that these effects have been stable over the generations included in the SASH survey.

\section{Discussion}

The data reported here document a high lifetime prevalence of psychiatric disorders in South Africa, with 30\% of respondents reporting a lifetime history of at least one of the DSM-IV/CIDI 
Table 3 Age in years at selected percentiles on the standardised age-at-onset distributions of psychiatric disorders with projected lifetime risk at age 75 years

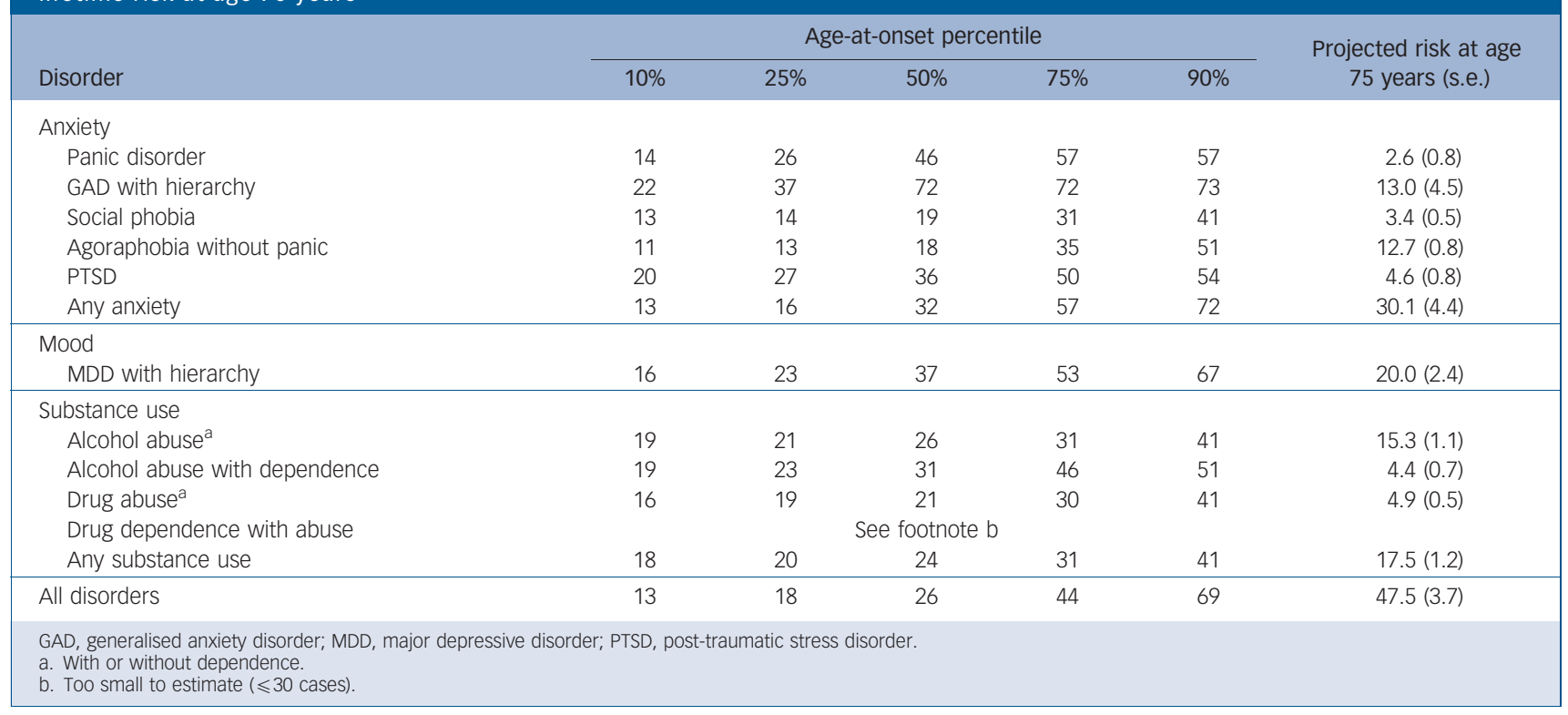

disorders considered in the survey. This is not as high a prevalence as in the USA, where approximately half the population meets lifetime criteria for one or more DSM-IV/CIDI disorders. ${ }^{5}$ However, it is considerably higher than the estimate found in a recent survey of Yoruba-speaking areas of Nigeria ${ }^{12}$ and higher than in the majority of other countries that have participated in the first wave of the WHO World Mental Health Survey Initiative. ${ }^{1}$

Examining the association of socio-demographic variables with psychiatric disorders provides an initial approach to understanding contributors to these prevalence rates. The associations of psychiatric disorder with gender (female gender associated with mood and anxiety disorders, male gender associated with substance use disorders) are consistent with those found in many other countries, whether low- or high-income. Other findings may, however, point to the importance of local factors; the lack of an association between very low income and substance use disorders suggests the possibility that at least some disposable income is required for the purchase of alcohol (the most commonly misused substance in South Africa) and other substances.

It is notable, however, that there were few differences in lifetime prevalence, or in age at onset of psychiatric disorder, by ethnic group. There was an increased lifetime prevalence of substance use disorders in the Coloured group; although this group is a diverse one, it was given a distinct status during apartheid rule, and the 'dop' system of paying Coloured workers on wine farms with alcohol was one important contributor to substance misuse in this community. Although there are clear links between

\begin{tabular}{|c|c|c|c|c|c|c|c|}
\hline \multirow[b]{2}{*}{ Disorder } & \multicolumn{4}{|c|}{ Birth cohort } & \multirow[b]{2}{*}{$\chi^{2}$} & \multirow[b]{2}{*}{ d.f. } & \multirow[b]{2}{*}{$P^{a}$} \\
\hline & $\begin{array}{l}18-34 \text { years } \\
\text { OR }(95 \% \mathrm{Cl})\end{array}$ & $\begin{array}{l}35-49 \text { years } \\
\text { OR }(95 \% \mathrm{Cl})\end{array}$ & $\begin{array}{l}\text { 50-64 years } \\
\text { OR (95\% Cl) }\end{array}$ & $\begin{array}{c}65+\text { years } \\
\text { OR }(95 \% \mathrm{Cl})\end{array}$ & & & \\
\hline Panic disorder & $3.0 \quad(0.4-20.2)$ & $5.0 \quad(0.8-30.2)$ & $2.2(0.4-13.5)$ & $1.0(1.0-1.0)$ & 7.6 & 3 & 0.054 \\
\hline GAD with hierarchy & $0.8 \quad(0.2-3.1)$ & $1.2(0.4-4.0)$ & $1.0(0.3-3.1)$ & $1.0(1.0-1.0)$ & 2.8 & 3 & 0.420 \\
\hline Social phobia & $3.2(0.7-14.8)$ & $3.1 \quad(0.6-15.2)$ & $2.0(0.6-7.3)$ & $1.0(1.0-1.0)$ & 2.4 & 3 & 0.487 \\
\hline Agoraphobia without panic & $2.5^{*}(1.4-4.5)$ & $1.9 *(1.1-3.4)$ & $1.3(0.6-2.5)$ & $1.0(1.0-1.0)$ & 19.1 & 3 & $<0.001$ \\
\hline PTSD & $2.2(0.4-11.0)$ & $1.0(0.3-3.4)$ & $0.7 \quad(0.2-2.6)$ & $1.0(1.0-1.0)$ & 12.4 & 3 & 0.006 \\
\hline Any anxiety disorder & $2.3^{*}(1.3-4.0)$ & $1.8 *(1.1-3.1)$ & $1.3(0.8-2.1)$ & $1.0(1.0-1.0)$ & 16.5 & 3 & 0.001 \\
\hline MDD with hierarchy & $9.6 *(5.5-16.7)$ & $5.5^{*}(3.1-9.9)$ & $2.5^{*}(1.4-4.4)$ & $1.0(1.0-1.0)$ & 95.6 & 3 & $<0.001$ \\
\hline Any mood disorder & $9.6 *(5.5-16.7)$ & $5.5^{*}(3.1-9.9)$ & $2.5^{*}(1.4-4.4)$ & $1.0(1.0-1.0)$ & 95.6 & 3 & $<0.001$ \\
\hline Alcohol abuse with/without dependence & $2.4^{*}(1.1-5.1)$ & $1.4 \quad(0.7-2.7)$ & $1.0 \quad(0.5-1.9)$ & $1.0(1.0-1.0)$ & 21.6 & 3 & $<0.001$ \\
\hline Alcohol dependence with abuse & $3.7 *(1.2-11.9)$ & $2.3 \quad(0.7-7.1)$ & $0.9 \quad(0.2-3.7)$ & $1.0(1.0-1.0)$ & 13.1 & 3 & 0.004 \\
\hline Drug abuse with/without dependence & $5.4^{*}(1.5-19.0)$ & $3.1 \quad(0.9-10.2)$ & $1.3(0.3-5.3)$ & $1.0(1.0-1.0)$ & 18.4 & 3 & $<0.001$ \\
\hline Drug dependence with abuse & & See $f$ & lote b & & & & \\
\hline Any substance use disorder & $2.6^{*}(1.3-5.4)$ & $1.5(0.8-2.9)$ & $1.0(0.6-1.9)$ & $1.0(1.0-1.0)$ & 29.1 & 3 & $<0.001$ \\
\hline Any disorder & $3.0 *(2.1-4.2)$ & $2.0 *(1.5-2.7)$ & $1.3(0.9-1.8)$ & $1.0(1.0-1.0)$ & 76.4 & 3 & $<0.001$ \\
\hline \multicolumn{8}{|c|}{$\begin{array}{l}\text { GAD, generalised anxiety disorder; MDD, major depressive disorder; PTSD, post-traumatic stress disorder. } \\
\text { a. Based on discrete-time survival models with person-year as the unit of analysis; controls are time intervals. } \\
\text { b. Too small to estimate }(\leqslant 30 \text { cases). } \\
{ }^{*} P \leqslant 0.05 \text {. }\end{array}$} \\
\hline
\end{tabular}


ethnicity and access to healthcare in South Africa, ${ }^{13}$ other aspects of the relationship between ethnic group and psychiatric disorder may be more complex. Not the least important phenomenon to take into account may be the heterogeneity of the construct of ethnicity; although apartheid clearly disadvantaged Black South Africans and advantaged White ones, many local factors contributed to variance between individuals within these groups.

Examining prevalence estimates across cohorts and age at onset provides another approach to exploring the meaning of the prevalence rates found here. Prevalence estimates varied across cohorts for major depression, as in other surveys. ${ }^{5,14}$ However, this phenomenon was not seen in generalised anxiety disorder and PTSD, perhaps suggesting the importance of exposure to stress and trauma as risk factors for psychiatric disorders over many years in the local context. Particularly striking was the high prevalence $(13.3 \%)$ and early age at onset (21 years) of substance use disorders. This pattern is much more pronounced in recent than in earlier cohorts, suggesting that it is a relatively new problem in South Africa. The increasing prevalence of substance use disorders in successive cohorts has been found in many other countries, ${ }^{14}$ but the increase generally was found to begin in earlier cohorts than seen here. South Africa was to some extent cut off from worldwide trends of many sorts during the apartheid years, and a rise in substance use disorders might have occurred later on, during democratisation.

There are important limitations that should be noted, all of which are likely to make the lifetime prevalence estimates here conservative. ${ }^{5}$ People with psychiatric disorders have been shown in other countries to be less likely than others to participate in mental health surveys. ${ }^{15}$ There is a bias against reporting embarrassing behaviours and there are age-related underestimations of illness duration and failures to report past disorders. In addition, in view of time constraints, the interview did not inquire about several prevalent conditions.

Another important limitation of the survey is the lack of clinical validation of the CIDI in the South African study. Although results were reassuring in CIDI clinical validation studies carried out in conjunction with the World Mental Health surveys in the USA ${ }^{5}$ and Europe, ${ }^{16}$ the cultural heterogeneity of the South African sample might have adversely affected the diagnostic accuracy of the instrument. The high lifetime prevalence of agoraphobia without panic here, and the variability in age at onset of major depression and generalised anxiety disorder, for example, may warrant caution. Perhaps some of those captured within the category of agoraphobia have the avoidant symptoms of PTSD, or have specific phobia (which was not included in the South African study, and which is usually the most prevalent anxiety disorder and the one with earliest onset) or experience realistic fears of going outside. Overestimates of agoraphobia have occurred in previous epidemiological work. ${ }^{17,18}$

Nevertheless, the high lifetime prevalence estimates for psychiatric disorders found here are broadly consistent with previous work in South Africa. A community prevalence study of psychiatric morbidity in a rural Coloured village found a prevalence of psychiatric morbidity of $27.1 \%$, with the majority of cases diagnosed as depressive or anxiety disorder. ${ }^{19}$ A prevalence study in a township primary healthcare clinic found that depression (37\%), PTSD (20\%) and somatisation disorder (18\%) were the most common diagnoses. ${ }^{20}$ Such data have been criticised by those who argue that distress in low- to middle-income countries should not be conflated with the presence of psychiatric disorders, and who question the applicability of the DSM classification system to non-Western countries. ${ }^{21}$ There is growing acceptance, however, that psychiatric disorders, as classified by DSM-IV and diagnosed by instruments such as the CIDI, are accompanied by significant social and occupational impairment. Furthermore, research on pathogenesis and intervention has demonstrated that such disorders are associated with psychobiological dysfunction, and that efficacious and cost-effective treatments are available even in low-income nations. ${ }^{22,23}$ This is not to minimise the potentially important effects of cultural context on the experience and expression of psychiatric disorders.

The high estimated lifetime prevalence and relatively early onset of psychiatric disorders noted here, taken together with published data on associated impairment and cost-efficacy of treatment, and with the growing acceptance that people with mental illness have a right to treatment, have important policy implications. Rigorous data on the proportion of the health budget spent on mental health services in the South African setting are not readily available, but there is consensus that a gross lack of parity exists, with significant underfunding of mental health services and research. ${ }^{24}$ We hope that the data reported here represent a first step in documenting a level of need for care that is sufficiently compelling to provide impetus for changes in mental health policy in South Africa, with an appropriate increase in funding for mental health services.

Dan J. Stein, University of Cape Town; Soraya Seedat, University of Stellenbosch; Allen Herman, Medical University of Southern Africa, Pretoria; Hashim Moomal, University of the Witwatersrand, Johannesburg, South Africa; Steven G. Heeringa, University of Michigan, Ann Arbor, Michigan; Ronald C. Kessler, David R. Williams, Harvard University, Cambridge, Massachusetts, USA

Correspondence: Dan J. Stein, UCT Department of Psychiatry, Groote Shuur Hospital J-2, Anzio Road, Observatory 7925, Cape Town, South Africa. Email: dan.stein@uct.ac.za

First received 1 Aug 2006, final revision 10 Jul 2007, accepted 17 Jul 2007

\section{Acknowledgements}

The South African Stress and Health Study was carried out in conjunction with the World Health Organization World Mental Health (WMH) Survey Initiative. We thank the WMH staff for assistance with instrumentation, fieldwork and data analysis. These activities were supported by the US National Institute of Mental Health (R01MH070884), the John D. and Catherine T. MacArthur Foundation, the Pfizer Foundation, the US Public Health Service (R13-MH066849, R01-MH069864, and R01-DA016558), the Fogarty International Center (R13-MH066849, R01-MH069864, and R01-DA016558), the Fogarty International Center
(FIRCA R01-TW006481), the Pan American Health Organization, Eli Lilly \& Company, Ortho-McNeil Pharmaceutical, GlaxoSmithKline and Bristol-Myers Squibb. The South Africa Stress and Health Study was funded by grant R01-MH059575 from the National Institute of Mental Health and the National Institute of Drug Abuse, with supplemental funding from the South African Department of Health and the University of Michigan. D.J.S. and S.S. are also supported by the Medical Research Council of South Africa. D.J.S. has received research grants and/or consultancy honoraria from Astrazeneca, Eli Lilly, GlaxoSmithKline, research grants and/or consultancy honoraria from AstraZeneca, Eli Lilly, GlaxoSmithKline,
Lundbeck, Orion, Pfizer, Pharmacia, Roche, Servier, Solvay, Sumitomo and Wyeth. R.C.K. has received research grants and/or consultancy honoraria from Bristol-Myers Squibb, Eli Lilly, GlaxoSmithKline, Ortho-McNeil, Pfizer and Wyeth.

\section{References}

1 Demyttenaere K, Bruffaerts R, Posada-Villa J, Gasquet I, Kovess V, Lepine J-P Angermeyer MC, Bernert S, de Girolamo G, Morosini P, Polidori G, Kikkawa T, Kawakami N, Ono Y, Takeshima T, Uda H, Karam EG, Fayyad JA, Karam AN, Mneimneh ZN, Medina-Mora M-E, Borges G, Lara C, de Graaf R, Ormel J, Gureje $\mathrm{O}$, Shen $\mathrm{Y}$, Huang $\mathrm{Y}$, Zhang $\mathrm{M}$, Alonso J, Haro JM, Vilagut G, Bromet EJ, Gluzman S, Webb C, Kessler RC, Merikangas KR, Anthony JC, Von Korff MR, Wang PS, Brugha TS, Aguilar-Gaxiola S, Lee $S$, Heeringa S, Pennell BE, Zaslavsky AM, Chatterji S, Ustun TB. Prevalence, severity, and unmet need for treatment of mental disorders in the World Health Organization World Mental Health Surveys. JAMA 2004; 291: 2581-90.

2 Hirschowitz R, Orkin M. Trauma and mental health in South Africa. Soc Indic Res 1997; 41: 169-82.

3 Dunkle KL, Jewkes RR, Brown HC, Gray GE, McIntryre JA, Harlow SD. Genderbased violence, relationship power, and risk of HIV infection in women attending antenatal clinics in South Africa. Lancet 2004; 363: 1415-21.

4 Patel V, Kleinman A. Poverty and common mental disorders in developing countries. Bull World Health Organ 2003; 81: 609-15.

5 Kessler RC, Berglund P, Demler O, Jin R, Merikangas KR, Walters EE. Lifetime prevalence and age-of-onset distributions of DSM-IV disorders in the 
National Comorbidity Survey Replication. Arch Gen Psychiatry 2005; 62 : 593-602.

6 Wittchen $\mathrm{H}-\mathrm{U}$, Jacobi F. Size and burden of mental disorders in Europe - a critical review and appraisal of 27 studies. Eur Neuropsychopharmacol 2005; 15: $357-76$

7 Williams DR, Herman A, Kessler RC, Sonnega J, Seedat S, Stein DJ, Moomal H, Wilson CM. The South African Stress and Health Study: rationale and design. Metab Brain Dis 2004; 19: 135-47.

8 Kish, L. A procedure for objective respondent selection within the household. J Am Stat Assoc 1949; 44: 380-7.

9 Kessler RC, Ustun TB. The World Mental Health (WMH) Survey Initiative Version of the World Health Organization (WHO) Composite International Diagnostic Interview (CIDI). Int J Methods Psychiatr Res 2004; 13: 93-121.

10 American Psychiatric Association. Diagnostic and Statistical Manual of Mental Disorders (4th edn) (DSM-IV). 1994; APA.

11 Allison, PD. Discrete-time methods for the analysis of event histories. Social Methodol 1982; 13: 61-98.

12 Gureje O, Lasebikan VO, Kola L, Makanjuola VA. Lifetime and 12-month prevalence of mental disorders in the Nigerian Survey of Mental Health and Well-Being. Br J Psychiatry 2006; 188: 465-71.

13 Lalloo R, Myburgh NG, Smith MJ, Solanki GC. Access to health care in South Africa - the influence of race and class. S Afr Med J 2004; 94: 639-42.

14 WHO International Consortium in Psychiatric Epidemiology. Cross-national comparisons of the prevalences and correlates of mental disorders. Bull World Health Organ 2000; 78: 413-26.

15 Kessler RC, Wittchen H-U, Abelson JM, McGonagle KA, Schwarz, N, Kendler KS, Knauper B, Zhao S. Methodological studies of the Composite
International Diagnostic Interview (CIDI) in the US national comorbidity survey (NCS). Int J Methods Psychiatr Res 1998; 7: 33-5.

16 Haro J-M, Arbabzadeh-Bouchez S, Brugha TS, de Girolamo G, Guyer ME, Jin R., Lepine J-P, Mazzi F, Reneses B, Vilagut G, Sampson NA, Kessler RC. Concordance of the Composite International Diagnostic Interview Version 3.0 (CIDI 3.0) with standardized clinical assessments in the WHO World Mental Health Surveys. Int J Methods Psychiatr Res 2006; 15: 167-80.

17 Horwath E, Lish JD, Johnson J, Hornig CD, Weissman MM. Agoraphobia without panic: clinical reappraisal of an epidemiologic finding. Am J Psychiatry 1993; 150: 1496-501.

18 Wittchen $\mathrm{H}-\mathrm{U}$, Zhao S, Abelson JM, Abelson JL, Kessler RC. Reliability and procedural validity of UM-CIDI DSM-III-R phobic disorders. Psychol Med 1996; 26: 1169-77.

19 Rumble S, Swartz L, Parry C, Zwarenstein M. Prevalence of psychiatric morbidity in the adult population of a rural South African village. Psychol Med 1996; 26: 997-1007.

20 Carey PD, Stein DJ, Zungu-Dirwayi N, Seedat S. Trauma and posttraumatic stress disorder in an urban Xhosa primary care population: prevalence, comorbidity and service use patterns. J Nerv Ment Dis 2003; 191: 230-6.

21 Kirmayer L. The place of culture in psychiatric nosology: taijin kyofusho and DSM-III-R. J Nerv Ment Dis 1991; 179: 19-28.

22 Chisholm D, Sanderson K, Ayuso-Mateos JL, Saxena S. Reducing the global burden of depression: population-level analysis of intervention costeffectiveness in 14 world regions. Br J Psychiatry 2004; 184: 393-403.

23 Stein DJ, Gureje O. Depression and anxiety in the developing world: is it time to medicalise the suffering? Lancet 2004; 364: 233-4.

24 Seedat S, Emsley RA, Stein DJ. Land of promise: challenges and opportunities for research in South Africa. Mol Psychiatry 2004; 9: 891-2.

\section{Dementia with Lewy bodies}

\section{Ian McKeith}

Every seven seconds there is a new case of dementia worldwide. Pathological studies suggest that $10-15 \%$ of cases are dementia with Lewy bodies (DLB), a diagnosis unrecognised 15 years ago. The functional impairments and costs of managing this illness are twice those of Alzheimer's disease and one in four carers rates quality of life in DLB as 'worse than death'. Correct management brings significant benefits, but DLB is only part of a spectrum of Lewy body disorders including Parkinson's disease and autonomic failure, which present to psychiatrists, neurologists, geriatricians and general practitioners. To beat it we must talk more with colleagues and cut across specialty boundaries. 